\title{
Impact of injury-related mortality on life expectancy in Zhejiang, China based on death and population surveillance data
}

\author{
Fang-Rong Fei, Jie-Ming Zhong, Min Yu, Wei-Wei Gong, Meng Wang, Jin Pan, Hai-bin Wu and Ru-Ying Hu*
}

\begin{abstract}
Background: Life expectancy is a statistical measure of the average time an organism is expected to live. The purpose of this study was to evaluate the impact of injury-related mortality on life expectancy in Zhejiang Province.

Methods: Our study used standard life tables to calculate life expectancy and cause-removed life expectancy based on mortality data from the Zhejiang Chronic Disease Surveillance System.

Results: Life expectancy of residents in Zhejiang was 77.83 years in 2013, with females having a higher life expectancy than males. The decrease in life expectancy caused by injury-related deaths was 1.19 years, the effect of which was reduced for females and urban residents compared with males and rural residents. The greatest impact on life expectancy was road traffic injuries (RT/s), $(0.29$ years lost overall, 0.36 for men vs. 0.21 for women and 0 . 26 for urban residents vs. 0.31 for rural residents). The main causes were falls ( 0.29 years lost overall, 0.30 for men vs. 0.28 for women and 0.28 for urban residents vs. 0.30 for rural residents), followed by drowning (0.15 years lost), suicide ( 0.11 years lost), and poisoning (0.04 years). For children less than 5 years old and elders aged over 65 , drowning had a greater impact than falls.

Conclusions: Our findings indicate that injury deaths had a major impact on life expectancy in Zhejiang. More attention should be paid to road traffic injury, and preventive action should be taken to reduce injury-related deaths to increase life expectancy, especially in children under five years of age and the elders over 65 years of age.
\end{abstract}

Keywords: Injury-related deaths, Life expectancy, Loss of life

\section{Background}

Life expectancy is a statistical measure of the average time an organism is expected to live based on current mortality [1]. It is a significant indicator for assessing the health and economic and social development levels of residents [2-4]. Zhejiang Province is located along the shore of the East China Sea, and covers an area of 101.8 thousand square kilometres. It is comprised of 11 cities and 90 districts. The total population of the province is 55.08 million. Life expectancy increased from 74.88 years to 77.57 years between 2000 and 2012 in Zhejiang Province. However, more than 5 million residents die from injury each year, which accounts for $9.8 \%$

\footnotetext{
* Correspondence: ncdhuruying@163.com

Department of NCDs Control and Prevention, Zhejiang Provincial Centre for Disease Control and Prevention, 3399 Binsheng Road, Hangzhou 310051, China
}

(c) The Author(s). 2017 Open Access This article is distributed under the terms of the Creative Commons Attribution 4.0 International License (http://creativecommons.org/licenses/by/4.0/), which permits unrestricted use, distribution, and reproduction in any medium, provided you give appropriate credit to the original author(s) and the source, provide a link to the Creative Commons license, and indicate if changes were made. The Creative Commons Public Domain Dedication waiver (http://creativecommons.org/publicdomain/zero/1.0/) applies to the data made available in this article, unless otherwise stated. deaths increased from $18.69 \%$ in 2004 to $21.26 \%$ in 2011 among those aged 0-14 years [6]. Injuries account for over $30 \%$ of all potentially productive years of life lost (PPYLL) due to premature mortality in China [7]. The Zhejiang Health Statistics Yearbook ranks death from injury fifth among all causes of death in Zhejiang Province, accounting for $9.89 \%$ of total mortality recorded in The Zhejiang Chronic Disease Surveillance Information and Management System in 2013. Furthermore, injury is the top cause of death among those aged 0-18 years. Deaths from injury not only seriously threaten public health but also lead to a significant social and economic burden [8].

During the 12th Five-Year Plan of China [9], the Chinese government has increased the amount of attention paid to the improvement of residents' health and has set a goal of increasing life expectancy by one year. It will 
take effective health policies to achieve this goal. Injuries are one of the leading causes of death in Zhejiang Province, and this significantly affects life expectancy. The government can adopt effective measures of prevention and intervention to reduce injury-related deaths.

Limited research on the impact of injury-related deaths on life expectancy exists at the provincial level [10-16]. The purpose of our study is to examine the impact of injury-related deaths on the life expectancy of residents in Zhejiang Province using death and population surveillance data. Based on this study, we will carry out resident health surveys to calculate healthy life expectancy (HALE) and its influencing factors.

\section{Methods}

\section{Data collection}

Mortality data was collected from the Zhejiang Chronic Disease Surveillance Information and Management System, which was published by the Zhejiang Provincial Centre for Disease Control and Prevention (CDC) [17]. Zhejiang Province is comprised of 90 districts. Taking into account the social system, economics, population, education, health and other indicators, the data was organized hierarchically using correlation analysis, factor analysis and k-means clustering. Random cluster sampling methods were used to extract a variety of combinations of samples, using a comparison of sample statistics and the overall parameters to determine the sample size. The results showed that 30 representative districts (12 in urban areas and 18 in rural areas) were selected as surveillance regions in which the prospective populationbased cause of death surveillance system that was established, covered 16.6 million residents $(36.9 \%$ of the population in Zhejiang Province).

Death information is collected as follows: when a patient dies in the hospital, a doctor will write a 'medical certificate of death' based on the patient's cause of death within seven days. The proportion of in-hospital deaths in our study was $47.68 \%$. When someone dies outside of the hospital, a community doctor regularly reports the information [18]. According to the deceased's family and other residents, the general practitioners in township hospitals or community health service centres would diagnose the cause of death and fill in the 'medical certificate of death'. The proportion of these deaths in our study was $52.32 \%$. Causes of death were coded from V01 to Y89 based on the International Classification of Diseases, the 10th edition. Major causes of death included injury (ICD-10 codes V01-Y89), road traffic injuries (RTIs) (V01-V04, V06, V09-V80, V87, V89, V99), Falls (ICD-10 codes W00-W19), drowning (W65-W74), poisoning (X40-X49), fire (X00-X09), suicide (X60-X84), accidental suffocation (W75-W77, W81-W84), assault (X85-Y09), and undetermined intent (Y10-Y34) [6].
In practice, under-reporting is likely to occur in the Zhejiang Chronic Disease Surveillance Information and Management System, so the true mortality rates were under-estimated [19]. This study used the amount of under-reporting to adjust the crude mortality rates. The derived formula was the adjusted mortality rate $=$ crude mortality rate / ( 1 - rate of underreporting). The manuscript used mortality rates with under-reporting estimated at $4.93 \%$. . In 2013, for all deaths, the proportion of all causes of death was ill-defined at $3.30 \%$. The proportion of deaths due to unspecified injuries was $0.69 \%$.

\section{Calculation of life expectancy}

We used adjusted mortality rates to calculate life expectancy using the standard life table technique. Data were analysed using EXCEL 2010. Our study used the data of injury-related deaths from which we subtracted injuryrelated deaths from all-cause deaths to calculate causeremoved life expectancy using the accepted procedure. $[20,21]$. The key to calculating cause-eliminated life expectancy is to calculate the survival probability of every age group after removing a cause of death. We also estimated the impact of the different sub-populations and the different categories of injury on life expectancy.

\section{Results}

\section{Life expectancy of the Zhejiang Province population}

The life expectancy of residents of Zhejiang Province was 77.83 years in 2013 (75.72 years for males, 80.30 years for females). Estimated life expectancy for urban and rural residents was 79.20 years and 77.09 years, respectively (Table 1).

\section{Increases in life expectancy after removing injury-related} deaths in Zhejiang Province residents in 2013

In 2013, the mortality from injury in Zhejiang Province was 60.83 per $10^{4}$, and the mortality from injury in urban and in rural areas was 51.70 per $10^{4}$ and 65.93 per $10^{4}$, respectively. Females had a lower mortality rate than males $\left(52.08\right.$ per $10^{4}$ vs 69.39 per $\left.10^{4}\right)$. The life expectancy of Zhejiang Province residents was 79.02 years after adjusting for injury-related mortality. The increase in life expectancy after this adjustment was 1.19 years, showing that injuries represent the third most frequent cause of death after cancers (3.33 years) and cardiovascular diseases (1.57) (Fig. 1). The life expectancy for

Table 1 The life expectancy at birth of Zhejiang Province residents in 2013 (years)

\begin{tabular}{llll}
\hline Districts & Male & Female & Total \\
\hline Urban & 77.18 & 81.52 & 79.20 \\
Rural & 74.94 & 79.62 & 77.09 \\
Total & 75.72 & 80.30 & 77.83 \\
\hline
\end{tabular}




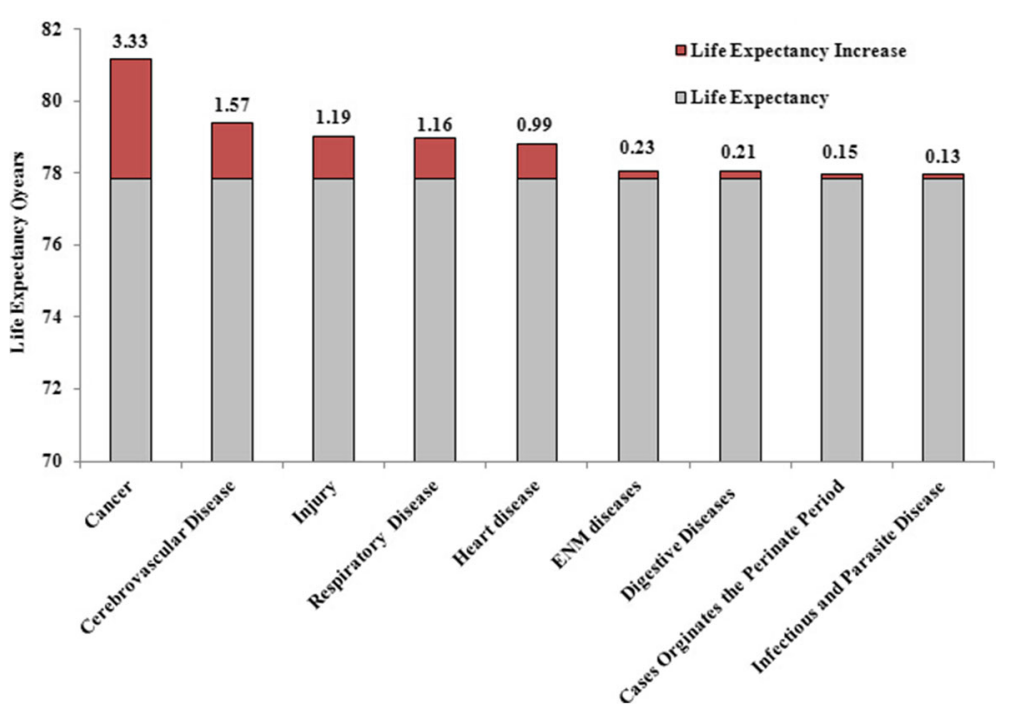

Fig. 1 After removing major causes of death, the life expectancy of Zhejiang residents in 2013

females and males was 81.31 and 77.06 years after removing injury-related deaths, respectively, and the increase of life expectancy for females and males was 1.02 years and 1.34 years, respectively.

After removing injury-related deaths, the life expectancy was 78.37 years for rural residents and 80.23 years for urban residents; the increase in life expectancy was 1.28 and 1.03 years, respectively. Furthermore, after removing injury-related deaths, the gains in life expectancy fell gradually as age increased. This study showed that deaths due to injuries had an impact on life expectancy in all age groups (Table 2, Fig. 2).

\section{Impacts of different categories of injury on life expectancy}

Our study showed an increase in life expectancy of 0.29 years after removing RTIs and falls, followed by drowning (0.15 years), suicide ( 0.11 years) and poisoning (0.04 years). The results after stratification for sex and region showed that the gains in life expectancy were 0.21 for females, 0.36 for males, 0.31 for rural residents and 0.26 for urban residents after removing RTIs (Tables 3 and 4).

In addition, after removing deaths due to different categories of injury, including RTIs, falls, drowning, suicide and poisoning, the gains in life expectancy were lower for females than for males. Residents from rural regions had a higher life expectancy than did residents from urban regions. However, for residents over age 65, removing deaths attributed to RTIs, falling, drowning and suicides had little impact on life expectancy. We found that removing deaths attributed to drowning had a greater impact than removing deaths attributed to falls for residents under 5 years old and those over 80 years old (Table 2, Fig. 2).

\section{Discussion}

Life expectancy is widely used to evaluate the status of residents' health and the burden caused by disease [22, 23]. Meanwhile, few studies have focused on the impact of removing causes of death on life expectancy in China $[1,8,18,24-27]$, especially at the national or provincial level. Injury-related death is a significant public health issue in our country. However, there have been no population-based studies that have examined the impact of deaths from injuries on life expectancy in Zhejiang Province. This research analysed the impact of injury-related deaths on life expectancy stratified by sex, age and region in Zhejiang Province. Our results indicate that injury-related deaths have a significant impact on life expectancy followed by cancer and circulatory system diseases. This information could explain the impact of disease types on life expectancy and is useful for prioritizing health-related projects for implementation by policy makers.

The results of our research showed that injury was the third largest cause of death affecting life expectancy in Zhejiang Province in 2013. The life expectancy for Zhejiang Province residents increased 1.19 years after removing injury-related deaths. Males (1.34 years) had a greater loss of life expectancy caused by injury than females (1.02 years). Our results are higher than those for most other studies in females. Wang Yuan et al. used data on injury deaths in 2010, and their research showed that the increase in life expectancy was 0.79 years for females after eliminating injury-related deaths [8]. Other research found that life expectancy increased for Italian woman after removing all categories of injury by 0.40 years [28]. Manuel et al. showed that the increase in life expectancy of women was 0.5 years after removing 
Table 2 After removing injury-related deaths, the increases in life expectancy for different age groups in Zhejiang Province residents in 2013

\begin{tabular}{|c|c|c|c|c|c|c|c|c|c|c|}
\hline \multirow[t]{2}{*}{ Age (years) } & \multirow{2}{*}{$\begin{array}{l}\text { Life Expectancy } \\
\text { (years) }\end{array}$} & \multirow{2}{*}{$\begin{array}{l}\text { Injury-removed } \\
\text { Life Expectancy } \\
\text { Increase (years) }\end{array}$} & \multicolumn{8}{|c|}{ Increase in Life Expectancy (Years) } \\
\hline & & & Injury & Road Traffic Injury (RTI) & Fall & Drowning & Poisoning & Fire & Suicide & $\begin{array}{l}\text { Accidental } \\
\text { Suffocation }\end{array}$ \\
\hline$\overline{0 \sim}$ & 77.83 & 79.02 & 1.19 & 0.29 & 0.29 & 0.15 & 0.04 & 0.01 & 0.11 & 0.03 \\
\hline $1 \sim$ & 77.35 & 78.50 & 1.15 & 0.29 & 0.29 & 0.14 & 0.04 & 0.01 & 0.11 & 0.01 \\
\hline $5 \sim$ & 73.48 & 74.57 & 1.09 & 0.28 & 0.28 & 0.11 & 0.03 & 0.01 & 0.11 & 0.01 \\
\hline $10 \sim$ & 68.55 & 69.60 & 1.05 & 0.27 & 0.28 & 0.09 & 0.03 & 0.01 & 0.11 & 0.00 \\
\hline $15 \sim$ & 63.62 & 64.63 & 1.01 & 0.27 & 0.27 & 0.08 & 0.03 & 0.01 & 0.11 & 0.00 \\
\hline $20 \sim$ & 58.68 & 59.66 & 0.98 & 0.26 & 0.27 & 0.07 & 0.03 & 0.01 & 0.10 & 0.00 \\
\hline $25 \sim$ & 53.74 & 54.69 & 0.95 & 0.25 & 0.27 & 0.07 & 0.03 & 0.01 & 0.09 & 0.00 \\
\hline $30 \sim$ & 48.82 & 49.73 & 0.91 & 0.24 & 0.26 & 0.06 & 0.03 & 0.01 & 0.09 & 0.00 \\
\hline $35 \sim$ & 43.92 & 44.79 & 0.87 & 0.22 & 0.26 & 0.06 & 0.02 & 0.01 & 0.08 & 0.00 \\
\hline $40 \sim$ & 39.04 & 39.87 & 0.83 & 0.21 & 0.26 & 0.05 & 0.02 & 0.01 & 0.07 & 0.00 \\
\hline $45 \sim$ & 34.24 & 35.03 & 0.79 & 0.19 & 0.25 & 0.05 & 0.02 & 0.01 & 0.07 & 0.00 \\
\hline $50 \sim$ & 29.59 & 30.31 & 0.72 & 0.17 & 0.24 & 0.04 & 0.02 & 0.01 & 0.06 & 0.00 \\
\hline $55 \sim$ & 25.06 & 25.72 & 0.66 & 0.15 & 0.23 & 0.04 & 0.01 & 0.01 & 0.05 & 0.00 \\
\hline $60 \sim$ & 20.76 & 21.33 & 0.57 & 0.12 & 0.21 & 0.03 & 0.01 & 0.01 & 0.04 & 0.00 \\
\hline $65 \sim$ & 16.66 & 17.16 & 0.50 & 0.09 & 0.20 & 0.03 & 0.01 & 0.01 & 0.03 & 0.00 \\
\hline $70 \sim$ & 13.00 & 13.43 & 0.43 & 0.05 & 0.19 & 0.02 & 0.01 & 0.01 & 0.03 & 0.00 \\
\hline $75 \sim$ & 9.36 & 9.75 & 0.39 & 0.04 & 0.19 & 0.02 & 0.00 & 0.01 & 0.02 & 0.00 \\
\hline $80 \sim$ & 6.34 & 6.70 & 0.36 & 0.02 & 0.19 & 0.01 & 0.00 & 0.01 & 0.02 & 0.00 \\
\hline 85 & 4.06 & 4.43 & 0.37 & 0.01 & 0.21 & 0.01 & 0.00 & 0.00 & 0.01 & 0.00 \\
\hline
\end{tabular}

categories of injury in Canada [29]. Another analysis of the data obtained from The Shanghai Vital Statistics System showed that life expectancy increased by 0.56 years for females in the Yangpu district in Shanghai after removing all categories of injuries [30]. By comparison, it suggested that the loss of life expectancy caused by injury was greater in females from the Zhejiang Province than in those from other regions. We also found that the impact of injury-related mortality on life expectancy was slightly greater in males than in females. This might be

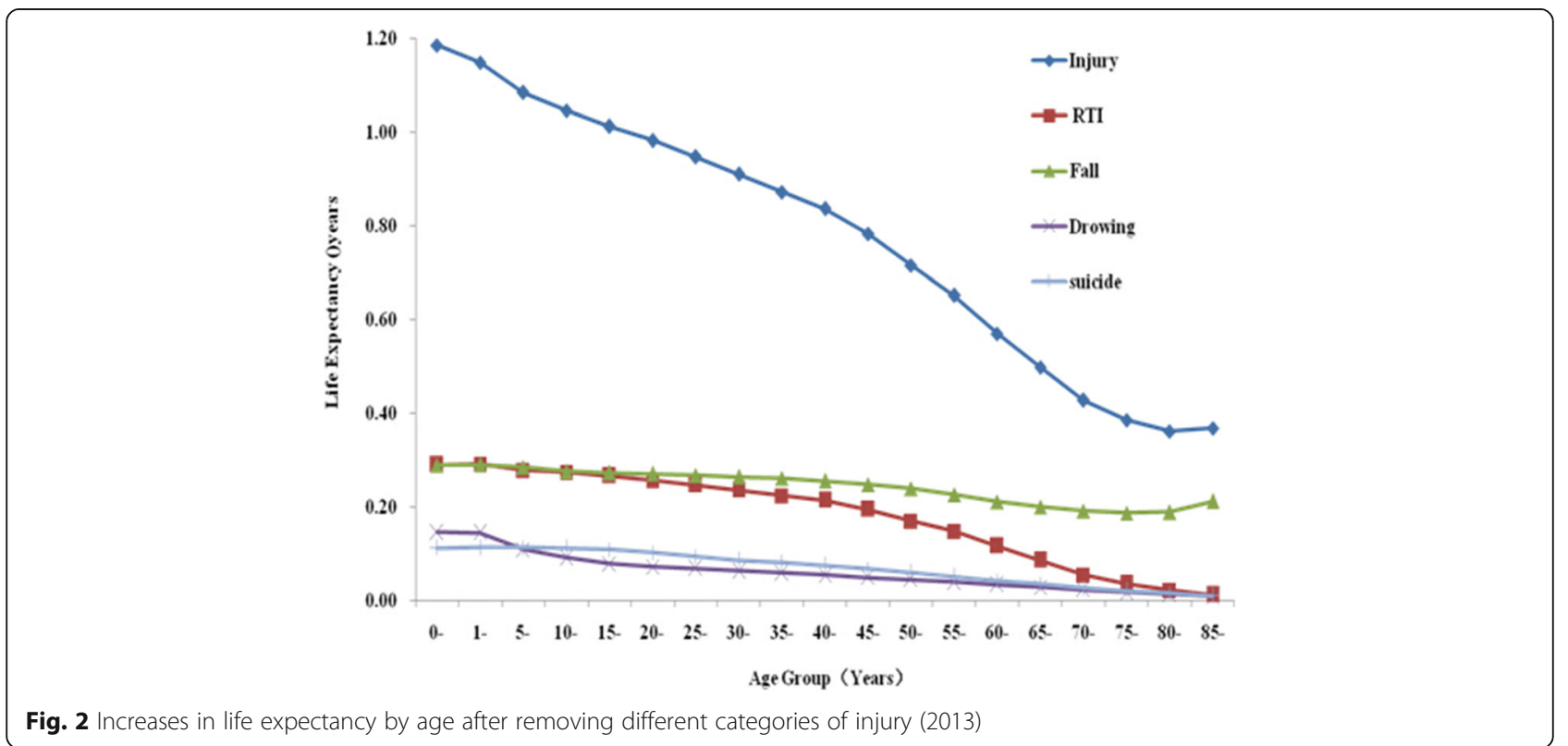


Table 3 After removing injury-related deaths, the increases in life expectancy at birth by gender in 2013

\begin{tabular}{|c|c|c|c|c|c|c|}
\hline \multirow[t]{2}{*}{ Rank } & \multicolumn{2}{|l|}{ All } & \multicolumn{2}{|l|}{ Male } & \multicolumn{2}{|l|}{ Female } \\
\hline & Injury-related Type & $\begin{array}{l}\text { Increase in Life } \\
\text { Expectancy }\end{array}$ & Injury Type & $\begin{array}{l}\text { Increase in Life } \\
\text { Expectancy }\end{array}$ & Injury Type & $\begin{array}{l}\text { Increase in Life } \\
\text { Expectancy }\end{array}$ \\
\hline 1 & RTI & 0.29 & RTI & 0.36 & RTI & 0.21 \\
\hline 2 & Fall & 0.29 & Fall & 0.30 & Fall & 0.28 \\
\hline 3 & Drowning & 0.15 & Drowning & 0.17 & Drowning & 0.11 \\
\hline 4 & suicide & 0.11 & suicide & 0.12 & suicide & 0.10 \\
\hline 5 & poisoning & 0.04 & poisoning & 0.05 & poisoning & 0.02 \\
\hline 6 & Accidental suffocation & 0.03 & Accidental suffocation & 0.03 & Accidental suffocation & 0.03 \\
\hline 7 & Fire & 0.01 & Fire & 0.01 & Fire & 0.01 \\
\hline
\end{tabular}

because males are exposed to relatively higher risks than females [31, 32]. For example, men have more opportunities to drive and to be engaged in heavy manual work requiring high strength and are prone to more alcohol consumption. These results suggest that we should carry out health education and take some effective interventions for men.

The impact of injury-related mortality on life expectancy differs between rural and urban residents. The decrease of life expectancy in 2013 was greater in rural residents than in urban residents (1.28 vs. 1.03 years) because of injury-related deaths. We found a lower awareness of the prevalence of injury risk factors. In addition, timely treatment in rural areas was not as prevalent as in urban areas [33]. Rural residents are in the majority, so their health status has a major impact on life expectancy in Zhejiang Province. This suggests there is a need to pay more attention to preventing and controlling deaths from injury in rural regions.

Our study suggests the highest increase in life expectancy occurs when removing deaths attributed to RTIs and falls from the different categories of injuries. These results are consistent with those of other studies. Wang Yuan et al. also showed that removing RTIs resulted in the highest increase life expectancy of all the categories

Table 4 After eliminating injury-related deaths, the increases in life expectancy at birth by region in 2013

\begin{tabular}{|c|c|c|c|c|}
\hline \multirow[t]{2}{*}{ Rank } & \multicolumn{2}{|l|}{ Urban Areas } & \multicolumn{2}{|l|}{ Rural Areas } \\
\hline & Injury Type & $\begin{array}{l}\text { Increase in Life } \\
\text { Expectancy }\end{array}$ & Injury Type & $\begin{array}{l}\text { Increase in Life } \\
\text { Expectancy }\end{array}$ \\
\hline 1 & RTI & 0.26 & RTI & 0.31 \\
\hline 2 & Fall & 0.28 & Fall & 0.30 \\
\hline 3 & suicide & 0.09 & suicide & 0.12 \\
\hline 4 & Drowning & 0.09 & Drowning & 0.17 \\
\hline 5 & poisoning & 0.02 & poisoning & 0.04 \\
\hline 6 & $\begin{array}{l}\text { Accidental } \\
\text { suffocation }\end{array}$ & 0.03 & $\begin{array}{l}\text { Accidental } \\
\text { suffocation }\end{array}$ & 0.03 \\
\hline 7 & Fire & 0.01 & Fire & 0.01 \\
\hline
\end{tabular}

of causes of injury deaths [8]. Moreover, our research found that with increasing age, the loss of life years attributed to different categories of injury-related deaths gradually decreases, indicating that injury-related deaths mainly affect young residents.

In our study, RTIs had the highest impact on life expectancy in most age groups. However, drowning and falling had the greatest effect on life expectancy for children and older residents, respectively. This study provides further evidence that relevant departments should develop injury prevention strategies. The programmes should prioritize specific health care projects and funding to increase life expectancy and promote health. The Chinese government has paid more attention to the improvement of the health of residents. The government achieved the goal of increasing life expectancy by one year during the 12th Five-Year Plan of China [9]. We shall gladly make every effort towards realizing this goal. We should develop reasonable health policies to resolve the major issues. This study suggests that we should improve injury prevention programmes to reduce injuryrelated deaths in older residents and in children less than 5 years old. We should reduce RTIs, falling, suicide and drowning to improve life expectancy. To prevent RTIs, it is necessary to promote child safety-seat use and develop legislation to strengthen the enforcement of laws against drunk driving and not wearing seatbelts. To prevent falls, organizing the elderly to take part in the Tai Chi to improve the balance and muscle strength of is necessary. Meanwhile, it is also necessary to improve their living conditions and reduce risk factors in their environment, such as increasing the use of bathmats.

The study has several limitations. First, this study used under-reported mortality rates to adjust crude mortality rates. Our team carried out the underreporting survey of 30 representative districts of death surveillance to determine the level of under-reporting of mortality rates in 2013. However, the adjusted data may still be underestimated. Second, a small proportion of subjects who died outside of a hospital had the wrong cause of death 
listed. Third, we did not explain the impact of injury risks, and as the districts selected were in Zhejiang Province, our findings are not generalizable to the broader Chinese population. Therefore, in the future, we will use disabled adjusted life years (DALY) and health adjusted life expectancy (HALE) to evaluate the disease burden.

\section{Conclusions}

Injury-related deaths have a major impact on life expectancy in Zhejiang Province. After reducing injuryrelated deaths, the life expectancy will likely be increased, with special attention on reducing road traffic injuries and taking preventative actions with children under five years old and the elderly aged over 65 through measures such as public education and modification of behaviours.

Abbreviation

RTI: Road Traffic Injury

\section{Acknowledgements}

The authors thank their colleagues at the district Provincial Centres for Disease Control and Prevention in all 30 surveillance districts for their important contributions.

\section{Funding}

This study was supported by grant 2015KYB084 (Medicine and Health Care in Zhejiang Province Science and Technology Plan) and 2017RC017 (Medicine and Health Care in Zhejiang Province Science and Technology Platform Project).

\section{Availability of data and materials}

Please contact the corresponding author to request data.

\section{Authors' contributions}

F.R.F., M.Y. and R.Y.H. designed the study. W.W.G. collected and analyzed the data with M.W., J.P., H.B.W. Professors J.M.Z. and L.F. provided advice about study design for manuscript. All the authors have read and approved the final submitted manuscript.

\section{Ethics approval and consent to participate}

This study was approved by the ethics committee of Zhejiang Provincial Centre for Disease Control and Prevention.

\section{Consent for publication}

Not applicable.

\section{Competing interests}

The authors declare that they have no competing interests.

\section{Publisher's Note}

Springer Nature remains neutral with regard to jurisdictional claims in published maps and institutional affiliations.

Received: 15 June 2016 Accepted: 5 July 2017

Published online: 17 July 2017

\section{References}

1. Liu P, Li C, Wang $Y$, et al. The impact of the major causes of death on life expectancy in China: a 60-year longitudinal study. BMC Public Health. 2014; 14:1193. doi:10.1186/1471-2458-14-1193.

2. Forster DP. Income distribution and life expectancy. BMJ. 1992;304(6828): 715-6.
3. Sede Pl, Ohemeng W. Socio-economic determinants of life expectancy in Nigeria (1980 - 2011). Health Econ Rev. 2015;5:2. doi:10.1186/s13561-0140037-z. eCollection 2015

4. Tian K. The average life expectancy change of Chinese population and its influence on life insurance. Chin Insur. 2011;7:24-7. (In Chinese)

5. World Health Organization. Violence, injuries and disability biennial report, 2006-2007. Geneva: World Health Organization; 2008.

6. Yin ZX, Wu J, Luo JS, et al. Burden and trend analysis of injury mortality in China among children aged 0-14 years from 2004 to 2011. BMJ Open. 2015;5(7):e007307. doi:10.1136/bmjopen-2014-007307.

7. Wang SY, Li YH, Chi GB, Xiao SY, Ozanne-Smith J, Stevenson M, et al. Injuryrelated fatalities in China: an under-recognised public-health problem. Lancet. 2008:372:1765-73. doi:10.1016/S0140-6736(08)61367-7. Epub 2008 Oct 17

8. Wang Y, Ji CR, Zhou MG. The nationwide impact of injury-related deaths on average life expectancy in China. Biomed Environ Sci. 2014;27:304-10. doi: 10.3967/bes2014.054.

9. The Twelfth Five-year Plan for National Economic and Social Development, the People's Republic of China. [http://www.gov.cn/201 1/h/content_1825838.htm] Accessed on 12 May 2016.

10. Li J, Luo C, de Klerk N. Trends in infant/child mortality and life expectancy in indigenous populations in Yunnan Province, China. Aust N Z J Public Health. 2008;32:216-23. doi:10.1111/j.1753-6405.2008.00219.x.

11. Fan J, Li GQ. Liu J1, Wang W, et al. impact of cardiovascular disease deaths on life expectancy in Chinese population. Biomed Environ Sci. 2014;27:1628. doi:10.3967/bes2014.037.

12. Zhao D, Liu J. The burden of cardiovascular disease and its impact on life expectancy in China. Eur Heart J. 2014;35:2625-6.

13. Canudas-Romo V, Liu L, Zimmerman L, Ahmed S, Tsui A. Potential gains in reproductive-aged life expectancy by eliminating maternal mortality: a demographic bonus of achieving MDG 5. PLoS One. 2014;9:86-94. doi:10. 1371/journal.pone.0086694. eCollection 2014

14. Xu Y, Zhang W, Yang R, et al. Infant mortality and life expectancy in China. Med Sci Monit. 2014:20:379-85. doi:10.12659/MSM.890204.

15. Fang XH, Zimmer Z, Kaneda T. Stroke and active life expectancy among older adults in Beijing. China Disabil Rehabil. 2009;31:701-11. doi:10.1080/ 09638280802305945

16. Wen $H$, Zhang $Y X$, Pan et al. JX Influence of major death causes on life expectancy in residents from surveillance points in Guizhou, 2012, Modern Preventive Medicine. 2014;41(7):1304-7. (In Chinese).

17. Yu M, Zhao HJ, Rao KQ. Selection of public health surveillance sample for Zhejiang Province. Chin J Health Stat. 2002;19:151-4. In Chinese

18. Li GQ, Fan J, Liu J, et al. Impact of cerebrovascular disease mortality on life expectancy in China. Biomed Environ Sci. 2014;27:169-75. doi:10.3967/ bes2014.038.

19. Wang L, Ma LM, Zhou MG. Characteristics of under-reporting of mortality surveillance from 2006 to 2008 in China. Chin J Prev Med. 2011:45:0-1. (In Chinese)

20. Zongzan N. Health statistics. Beijing: People's Medical Publishing House; 2001. p. 197-205. (In Chinese)

21. Chiang C. The life table and its applications. Malabar: Robert E Krieger Publ Co; 1984.

22. Wilkinson RG. Income distribution and life expectancy. BMJ. 1992;304:165-8.

23. Deaton A. Health, inequality, and economic development. J Econ Lit. 2003; XLI:113-58.

24. Wang WX, Wu KX. Analysis on average life and death cause-eliminated life expectancy in Qishi. Corps Med. 2011;3:59-61. (In Chinese)

25. Chen XF, Wang J, Yang ZY. Analysis on injury death causes in Pengzhou from 2002 to 2006. J Occup Health Damage. 2007:22:210-2. (In Chinese)

26. Zhang Y, Wang LL. Analysis on death cause-eliminated life expectancy form. Chin Prev Med. 2009;10:380-2. (In Chinese)

27. Wang HG. Study on the Influence of Main Diseases to Life expectancy of Chinese Residents. Peking Union Medical College. 2011. (In Chinese).

28. Conti S, Farchi G, Masocco M, et al. The impact of the major causes of death on life expectancy in Italy. Int J Epidemiol. 1999;28:905-10. doi:10.1093/ije/28.5.905.

29. Manuel DG, Schultz SE, Kopec JA. Measuring the health burden of chronic disease and injury using health adjusted life expectancy and the health utilities index. J Epidemiol Community Health. 2002;56:843-50. doi:10.1136/ jech.56.11.843.

30. Guan XY, Li H. The main cause of residents death and loss of years in shanghai Yangpu district during 2010. Pract Prev Med. 2012;1:54-5. (In Chinese) 
31. Fenelon A, Chen LH, Baker SP. Major causes of injury death and the life expectancy gap between the United States and other high-income countries. JAMA. 2016;315(6):609-11. doi:10.1001/jama.2015.15564.

32. Hu Y, Wu L, Yu X, et al. Analysis of injury death trends among women in Macheng City, China, 1984-2008. BMC Public Health. 2011;11:698. doi:10. 1186/1471-2458-11-698.

33. Wang N. National Disease Surveillance System: the cause of death surveillance data sets in. Beijing: Mil Med Sci. 2010;2012:20-130. (In Chinese)

Submit your next manuscript to BioMed Central and we will help you at every step:

- We accept pre-submission inquiries

- Our selector tool helps you to find the most relevant journal

- We provide round the clock customer support

- Convenient online submission

- Thorough peer review

- Inclusion in PubMed and all major indexing services

- Maximum visibility for your research

Submit your manuscript at www.biomedcentral.com/submit
Biomed Central 